\title{
Zakres kruchości wysokotemperaturowej złączy spawanych stopu Inconel 625
}

\author{
Range of high-temperature embritlement \\ for Inconel 625 welded joint
}

\section{Streszczenie}

Stopy niklu ze względu na dobre właściwości mechaniczne w wysokich temperaturach, wysoką odporność na pełzanie oraz odporność na utlenianie znalazły zastosowanie m.in. w przemyśle energetycznym i lotniczym. Głównym problemem podczas spawania tych stopów są pęknięcia gorące, które mogą wystąpić zarówno w spoinie jak i strefie wpływu ciepła. Dyskwalifikują one złącze spawane do użytkowania i o ile to możliwe, wymagają naprawy. Za główną przyczynę pękania gorącego uważa się obniżenie plastyczności metalu w zakresie kruchości wysokotemperaturowej (ZKW) oraz odkształcenia złącza spawanego podczas spawania. Szerokość zakresu kruchości wysokotemperaturowej zależy od właściwości materiału oraz warunków spawania, tj. parametrów spawania, geometrii złącza, cyklu cieplnego, kształtu i sztywności konstrukcji.

W pracy wykonano technologiczną próbę transvarestraint, która umożliwiła wyznaczenie zakresu kruchości wysokotemperaturowej stopu Inconel 625 oraz wskaźników odporności materiału na pękanie gorące: progu pękania, krytycznej prędkości odkształcenia i krytycznej temperaturowej intensywności odkształcenia. W celu określenia mechanizmu pękania gorącego przeprowadzono badania metalograficzne i fraktograficzne na podstawie których stwierdzono, że pękanie gorące przebiega w zakresie temperatur ZKW w wyniku rozerwania cienkiej warstewki cieczy po granicach kryształów narastających w spoinie.

Słowa kluczowe: zakres kruchości wysokotemperaturowej, pękanie gorące, próba transvarestraint, stop Inconel 625

\section{Abstract}

Nickel alloys, due to their good mechanical properties in elevated temperature, high creep resistance and oxidation resistance, are used in power and aircraft industries. The main difficulty during welding of nickel alloys are hot cracks, which can appear in weld and heat affected zone. Hot cracks cause disqualification of welded joints to using and should be repair if it is possible. The main reason of hot cracks formulation is decrease in metal ductility in high-temperature brittleness range (HTBR) and metal deformation during welding. Width of HTBR depend on material properties and welding condition i.e. welding parameters, joint geometry, thermal cycle, shape and stiffness of weld.

In this paper transvarestrain test was performed. This test allows to determine the width of the range of hightemperature brittleness HTBR, threshold, critical strain speed of the weld CSS and critical temperature strain intensity CST.Metallographic and fractographic research enabled to define mechanism of hot cracking. It was found that hot cracks formulate as a results of disruption of liquid film on crystals boundaries.

Keywords: high brittleness temperature range, hot cracking, transvarestrain test, Inconel 625 alloy

\section{Wstęp}

Rosnące wymagania przemysłu energetycznego wynikające z dążenia do uzyskania większych sprawności bloków energetycznych, wymusza stosowanie nowych rozwiązań w zakresie projektowania i budowy kotłów na parametry nadkrytyczne i ultranadkrytyczne. Jednym z kierunków rozwoju jest stosowanie nowych materiałów np. stopów niklu. Charakteryzują się one znaczną wytrzymałością w wysokiej temperaturze, odpornością na pełzanie i odpornością na utlenianie. Pozwalają na zwiększenie temperatury pracy bloków energetycznych, a tym samym zwiększenie ich sprawności. Stopy niklu są stopami dobrze spawalnymi, jednak są skłonne do pękania gorącego, dlatego podczas spawania należy przestrzegać zaleceń technologicznych. Pęknięcia gorące, mogą wystąpić zarówno w spoinie

Dr inż. Agata Turowska; dr hab. inż. Janusz Adamiec, prof. nzw. PŚı - Politechnika Śląska.

Autor korespondencyjny/Corresponding author. Agata.Turowska@polsı.pl 
jak i strefie wpływu ciepła. Dyskwalifikują one poprawność złączą spawanego i nie pozwalają na jego eksploatację. Dlatego istotnym jest ocena i określenie kryteriów skłonności do pękania gorącego stopów niklu podczas spawania [1 $\div 3]$.

Jedną z metod oceny skłonności materiału do pękania na gorąco jest wyznaczenie zakresu kruchości wysokotemperaturowej (ZKW); im szerszy ZKW tym większa skłonność materiału do powstania pęknięć gorących. Zakres ten można wyznaczyć w próbach technologicznych, które mogą być prowadzone w warunkach, gdy odkształcenie jest regulowane rodzajem konstrukcji, rozmiarami złącza, kolejnością i parametrami układania ściegów (próba kołowa, o zmiennej sztywności ze spoiną czołową, Tekkena, Fisco, Houldcrofta) lub gdy odkształcenie jest wymuszone (próba Transvarestraint, Varestraint) [4].

Za górną granicę ZKW uważa się temperaturę utraty wytrzymałości materiału podczas nagrzewania (NST - nil strenght temperature). Jest to temperatura wyznaczana podczas nagrzewania, w której wytrzymałość materiału spada do zera. W jej pobliżu oraz powyżej niej, materiał nie jest w stanie przenosić obciążeń mechanicznych. Dolną granicę ZKW stanowi temperatura odzyskania plastyczności materiału podczas chłodzenia (DRT - ductility recovery temperature). W próbie transvarestraint za dolną granicę ZKW przyjmuję się temperaturę końca pęknięcia $\left(T_{k}\right)[4 \div 6]$.

W pracy określono skłonność do pękania gorącego stopu Inconel 625, na podstawie technologicznej próby transvarestraint, która umożliwiła wyznaczenie zakresu kruchości wysokotemperaturowej oraz wskaźników odporności na pękanie gorące.

\section{Materiał do badań i metodyka}

Do badań wykorzystano stop niklu Inconel 625 zawierający chrom (>20\%), molibden (ok. 10\%), żelazo (ok. 5\%), niob (ok. 3\%) oraz inne pierwiastki w ilości poniżej $3 \%$. W celu oceny skłonności do pękania gorącego spoin ze stopu Inconel 625 przeprowadzono technologiczną próbę transvarestraint. Polega ona na szybkim zginaniu badanych próbek, w trakcie przetapiania, na cylindrycznym bloku matrycowym, tak aby dokładnie odtwarzały jego krzywiznę. Wielkość odkształcenia zależy od grubości zginanej próbki i promienia krzywizny bloku matrycowego.

Próbę transvarestraint przeprowadzono na płytkach o wymiarach: $5 \times 40 \times 60 \mathrm{~mm}$. Próbki były przetapiane metodą TIG, prądem przemiennym o natężeniu 140 A, w osłonie argonu o przepływie $8 \mathrm{l} / \mathrm{min}$. Parametry procesu dobrano tak, aby uzyskać pełne przetopienie. Prędkość przetapiania wynosiła 0,95 mm/s. Podczas przetapiania symulowano odkształcenie na trzpieniach gnących o promieniach krzywi-

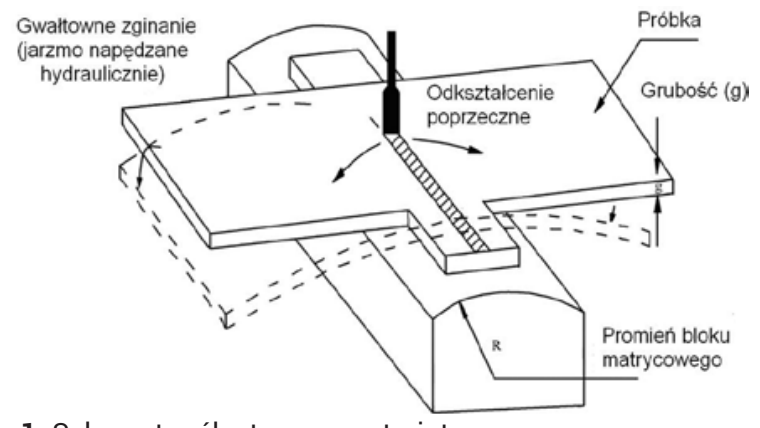

Rys. 1. Schemat próby transvarestraint

Fig. 1. Scheme of transvarestraint test

zny: $17,38,55,85,110,135$ i 150 mm. Schemat próby przedstawiono na rysunku 1.

Do oceny skłonności do pękania gorącego stopu Inconel 625 koniecznym jest wyznaczenie temperatury utraty wytrzymałości (NST) oraz równania cyklu cieplnego $T=f(t)$.

Temperaturę NST wyznaczono na symulatorze Gleeble 3800 , nagrzewając próbki z szybkością $20^{\circ} \mathrm{C} / \mathrm{s}$ do temperatury $1200{ }^{\circ} \mathrm{C}$, a następnie z szybkością $1{ }^{\circ} \mathrm{C} / \mathrm{s}$ do temperatury zerwania. Temperaturę NST określono na podstawie 5 testów. Równanie cyklu cieplnego określono wykonując symulację rozkładu temperatury $\mathrm{w}$ strefie wpływu ciepła i rejestrując zmiany temperatury w czasie w poszczególnych punktach SWC, także na symulatorze Gleeble 3800 .

\section{Wyniki badań i analiza}

Uzyskane w próbie transvarestraint wyniki i obliczenia zestawiono w tablicy I. Wielkość odkształcenia wyznaczono według zależności:

$$
\varepsilon=\frac{g}{2 R} \cdot 100 \%
$$

gdzie: $\varepsilon$ - wielkość odkształcenia (\%), g - grubość zginanej próbki $(\mathrm{mm}), \mathrm{R}$ - promień krzywizny bloku matrycowego $(\mathrm{mm})$.

Następnie wyznaczono: długość najdłuższego pęknięcia w osi spoiny, sumę długości wszystkich pęknięć oraz określono próg pękania jako odkształcenie, przy którym nie ujawniono pęknięć gorących. Czas rozwoju pęknięcia obliczono z zależności:

$$
t_{\max }=\frac{L_{\max }}{v_{s}}
$$

gdzie: $t_{\max }$ - czas rozwoju pęknięcia (s), $L_{\max }$ - najdłuższe pęknięcie $(\mathrm{mm}), \mathrm{v}_{\mathrm{s}}$ - prędkość spawania $(\mathrm{mm} / \mathrm{s})$.

Tablica I. Wyniki próby transvarestrain dla stopu Inconel 625

\begin{tabular}{|c|c|c|c|c|c|c|c|}
\hline Lp. & $\begin{array}{c}\text { Promień } \\
\text { trzpienia } \\
\mathrm{R}(\mathrm{mm})\end{array}$ & $\begin{array}{c}\text { Prędkość } \\
\text { spawania Vs } \\
(\mathrm{mm} / \mathrm{s})\end{array}$ & $\begin{array}{l}\text { Najdłuższe } \\
\text { pęknięcie } \\
\text { Li }_{\text {max }} \text { mm }\end{array}$ & Liczba pęknięć & $\begin{array}{l}\text { Suma długości } \\
\text { wszystkich } \\
\text { pęknięć } \\
\sum L_{i}(\mathrm{~mm})\end{array}$ & $\begin{array}{c}\text { Czas rozwoju } \\
\text { pęknięcia } \\
t_{\max }(\mathrm{s})\end{array}$ & $\begin{array}{c}\text { Wielkość } \\
\text { odkształcenia } \\
\varepsilon(\%)\end{array}$ \\
\hline 1 & 150 & 0,95 & 0 & 0 & 0 & 5,37 & 1,67 \\
\hline 2 & 135 & 0,95 & 3 & 7 & 11,7 & 5,16 & $1,85\left(\varepsilon_{\mathrm{p}}\right)$ \\
\hline 3 & 110 & 0,95 & 3,4 & 10 & 19,1 & 4,32 & 2,27 \\
\hline 4 & 85 & 0,95 & 3,8 & 14 & 25,5 & 4 & 2,94 \\
\hline 5 & 55 & 0,95 & 4,1 & 15 & 30,9 & 3,58 & 4,55 \\
\hline 6 & 38 & 0,95 & 4,9 & 19 & 40,2 & 3,16 & 6,58 \\
\hline 7 & 17 & 0,95 & 5,1 & 21 & 48,1 & 0 & 14,71 \\
\hline
\end{tabular}

Table I. Results of the transvarestrain for Inconel 625 alloy 
Na podstawie uzyskanych w próbie transvarestraint wyników wyznaczono krytyczną temperaturową intensywności odkształcenia (CSS) oraz krytyczną prędkość odkształcenia (CST). Są to wskaźniki stanowiące kryterium pękania gorącego dla stopu Inconel 625 podczas spawania. CSS jest rozumiana jako minimalna temperaturowa intensywność odkształcenia przy której nie powstaje pęknięcie i jest określana jako tangens kąta pomiędzy styczną do krzywej rozwoju pęknięcia a osią odkształcenia (rys. 2a). CST jest określany jako tangens kąta pomiędzy styczną do krzywej odkształcenia a osią temperatury i jest kryterium opisującym minimalną prędkość wymuszonego odkształcenia przy której nie powstaje pęknięcie gorące (rys. 2b). Dla stopu Inconel 625: CSS $=0,81 / \mathrm{s}$, CST $=10 * 10-31 / \mathrm{oC}$. Zakres kruchości wysokotemperaturowej stopu wyznaczono jako różnicę pomiędzy temperaturą utraty plastyczności (NST) a temperaturą końca pęknięcia (Tk). Dla stopu Inconel 625 zakres kruchości wysokotemperaturowej wynosi $282{ }^{\circ} \mathrm{C}$ i jest w zakresie temperatury od 998 do $1280^{\circ} \mathrm{C}$ (rys. 2b).

a)

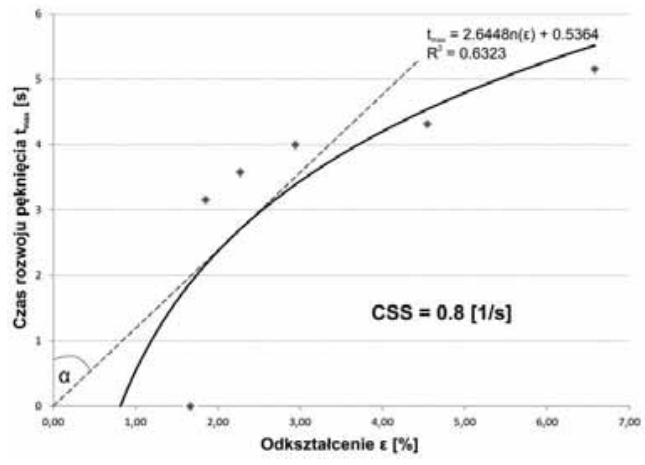

b)

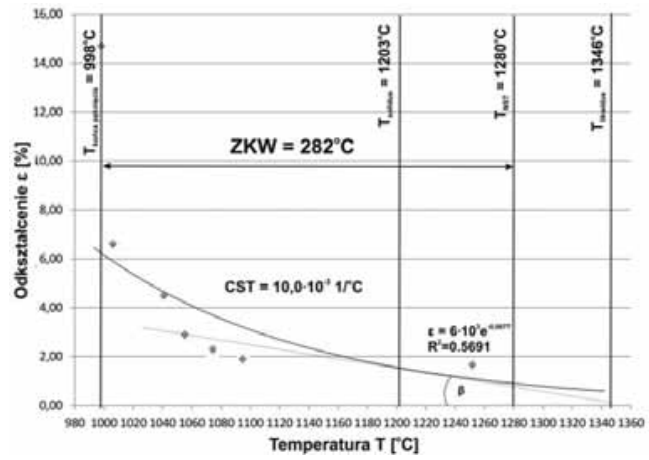

Rys. 2. Wyniki próby transvarestraint dla stopu Inconel 625: a) zależność czasu rozwoju pęknięcia w funkcji odkształcenia $\mathrm{t}_{\max }=\mathrm{f}(\varepsilon)$, b) krzywa plastyczności $\varepsilon=\mathrm{f}(\mathrm{T})$

Fig. 2. Results of transvarestraint test for Inconel 625 alloy: a) relation of the time of cracking development $t_{\max }=f(\varepsilon)$, b) plasticity curve $\varepsilon=f(T)$
Próbki po badaniach odporności na pękanie gorące w warunkach wymuszonego odkształcenia zostały wykorzystane do badań metalograficznych i fraktograficznych. Przykładowe wyniki obserwacji pokazano na rysunku 3.

Badania mikroskopowe próbek po próbie transvarestrain ujawniły pęknięcia gorące w spoinie i strefie wpływu ciepła. Na rysunku 3a przedstawiono lico przetopienia próbki odkształcanej na bloku o promieniu $38 \mathrm{~mm}$ z widocznymi pęknięciami gorącymi inicjowanymi na brzegu jeziorka spawalniczego. Na rysunku 3b przedstawiono makrostrukturę przetopienia z ujawnionymi pęknięciami w spoinie i strefie wpływu ciepła pod powierzchnią metalu i niewidocznymi od strony lica. Pęknięcia te powstają w obszarze stało-ciekłym podczas krystalizacji spoiny.

$\mathrm{Na}$ rysunkach 3c,d,e przedstawiono powierzchnię swobodną pęknięcia, na której widoczne są pojedyncze kolumnowe dendryty z ramionami wtórnymi. Wskazuje to na swobodną możliwość ich narastania w cieczy. Brak śladów ciągnięcia na ich powierzchni wskazuje, że podczas powstawania pęknięcia były otoczone ciekłym metalem.

Pęknięcia gorące powstające w ZKW w stopie Inconel 625 charakteryzują się ułożeniem prostopadłym do powierzchni lica spoiny (rys. 3c-e). Pęknięcia te rozwijają się po granicach kryształów austenitu, co potwierdzają również obserwowane na powierzchni pęknięcia ramiona dendrytów spoiny (rys. 3c-e).

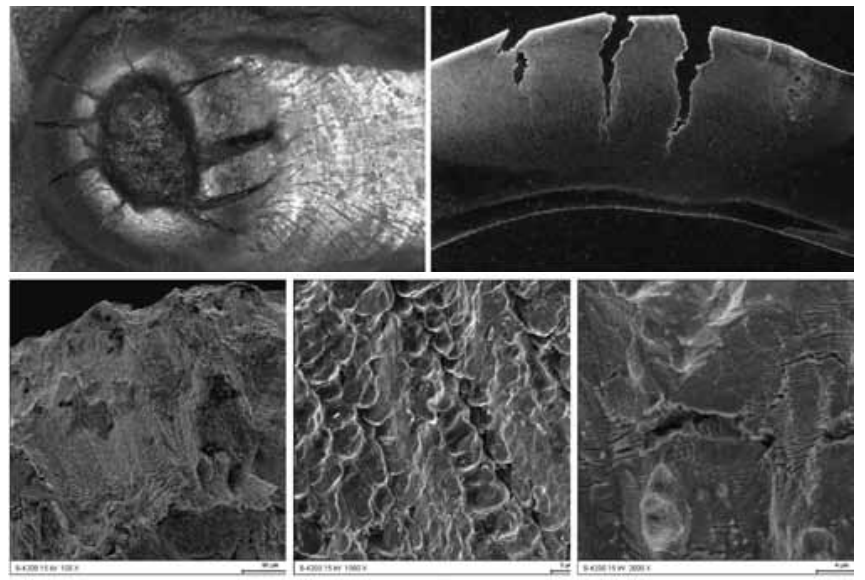

Rys. 3. Próbka ze stopu Inconel 625 po próbie transvarestraint: a) lico przetopienia, promień gięcia $38 \mathrm{~mm}$, b) pęknięcia na przekroju poprzecznym przetopienia, c) pęknięcie gorące, SEM, pow.100x, d) powierzchnia swobodna pęknięcia, SEM, pow.1000x, e) obszar pęknięcia, SEM, pow.2000x

Fig. 3. Sample of Inconel 625 alloy after transvarestraint test: a) faces of weld penetration, bend radius $38 \mathrm{~mm}, \mathrm{~b}$ ) cracks on cross section of weld penetration, c) hot cracking SEM, magn.100x, d) free surface on crack, SEM, magn.1000x, e) surface of crack area, SEM, magn. $2000 x$

\section{Podsumowanie}

Przeprowadzenie technologicznej próby transvarestraint, tj. próby przetapiania materiału w warunkach wymuszonego odkształcenia pozwoliło na wyznaczenie zakresu kruchości wysokotemperaturowej stopu Inconel 625 . Jako kryterium oceny skłonności do pękania gorącego w warunkach wymuszonego odkształcenia przyjęto próg pękania, krytyczną prędkość odkształcenia i krytyczną temperaturową intensywność odkształcania.

Uzyskane w próbie wyniki pozwoliły na wykreślenie zależności czasu rozwoju pęknięcia w funkcji odkształcenia oraz określenie krytycznej prędkości odkształcenia: CSS=0,8 1/s. Zależność odkształcenia w funkcji temperaturowej pozwoliła na wyznaczenie krytycznej temperaturowej intensywności odkształcenia: CST $=10,0 \cdot 10^{-3} 1 /{ }^{\circ} \mathrm{C}$. Są to wielkości, po których przekroczeniu stop Inconel 625 będzie pękać na gorąco w procesie spawania. Na podstawie zależności $\varepsilon=f(T)$ wyznaczono zakres kruchości wysokotemperaturowej stopu Inconel 625 w warunkach wymuszonego odkształcenia. Wynosi on $280^{\circ} \mathrm{C}$ i mieści się w zakresie temperatur $998-1280^{\circ} \mathrm{C}$. 
Uzyskane wyniki wskazują, że wraz ze wzrostem odkształcenia wzrasta liczba pęknięć oraz ich sumaryczna długość. Pojawiające się pęknięcia mają charakter krystalizacyjny. Przebiegają po granicach krystalitów, gdzie podczas stygnięcia pomiędzy wzrastającymi krystalitami znajdował się jeszcze ciekły metal. Analiza struktury powierzchni przełomu pęknięć gorących nadstopów niklu, które powstały w warunkach wymuszonego odkształcenia wskazuje, że pękanie następuje w wyniku rozerwania się warstewki cieczy na granicach krystalizujących kryształów austenitu.

Na tej postawie stwierdzono, że w celu uniknięcia pękania gorącego elementów spawanych ze stopu niklu Inconel 625 należy spawać z możliwie małymi odkształcenia (próg pękania jest poniżej 1,67\%), podczas procesu nie przekraczać wartości krytycznej CSS, spawać małą energią liniową łuku, oraz unikać intensywności odkształcenia w wyniku oddziaływania temperatury tak aby utrzymać CST poniżej wartości $10,0 \cdot 10^{-3} 1 /{ }^{\circ} \mathrm{C}$.

Praca sfinansowana w ramach Programu Badań Stosowanych finansowanego przez Narodowe Centrum Badań i Rozwoju, projekt pt.: "Technologia spawania laserem rur ożebrowanych ze stali austenitycznych i stopów niklu przeznaczonych do pracy w kotłach o parametrach nadkrytycznych i ultranadkrytycznych.", nr umowy PBS1/A5/13/2012

\section{Literatura}

[1] Huseman R.: Advanced (700oC) PF Power Plant. A Clean Coal European, Technology. Advanced Material for AD700 Boilers, Cesi Auditorium, Milano,2005.

[2] Adamiec J., Piliszko B.: Wysokotemperaturowa korozja elementów kotłów przemysłowych napawanych stopami niklu, Inżynieria Materiałowa, $\mathrm{nr}$ 6, 2007, s. 907-913.
[3] Inconel 625 i 686Adamiec J., Więcek M., Kokot G.: Technologia spawania laserowego rur ożebrowanych., Przegląd Spawalnictwa 5/2014, p.3-9.

[4] Tasak E. Metalurgia spawania. Wydawnictwo JAK, Kraków 2008.

[5] Gleeble 3800 Aplications, Welding Process Simulation 2000.

[6] Adamiec P., Dziubiński J., Gruszczyk A., Makosz P., Mazur M., Mazur W., Szymański A.: Metalurgia spawania. Wyd. Politechniki Śląskiej, Gliwice, 1992, Skrypty uczelniane nr 1679. 